\title{
The True Cost of Field Education is a Barrier to Diversifying Geosciences
}

\author{
DR. ANTOINETTE ABEYTA ${ }^{1}$, ANJALI M FERNANDES ${ }^{2}$, \\ ROBERT C MAHON ${ }^{3}$ AND TRAVIS SWANSON ${ }^{4}$ \\ ${ }^{1}$ University of New Mexico Gallup \\ ${ }^{2}$ Denison University \\ ${ }^{3}$ University of New Orleans \\ ${ }^{4}$ Georgia Southern University \\ Presenting Author: abeytaant@unm.edu
}

Fieldwork is considered critical to developing technical skills in geoscience education, and typical undergraduate degrees require $>\mathbf{3 0}$ days in the field. Tuition costs of enrolling in field camp are acknowledged as a barrier to participation in geosciences; however, the cost of participation in field activities may also include the cost of personal field gear (hiking boots, backpacks, etc.), travel, lost wages, and dependent care. To neutralize impacts of systemic bias on the future geoscience workforce, it is imperative that we (a) examine how the cost of field work presents barriers to participation, and (b) intentionally direct financial resources towards dismantling these barriers. We show that the financial burden associated with a week-long field endeavor, excluding potential tuition costs and including personal field gear, domestic air travel, lodging, dependent care and lost wages range from 1271 to 2,007 U.S. dollars (USD), and can be as large as 6,262 USD. This sum is likely to be out of reach for individuals from low-income groups and represents a fundamental barrier to diversifying participation in our field. Budgets for inclusive field research and education must account for and accommodate these financial challenges to broader participation. 